\title{
MODIFICAÇÕES NUCLEARES EM CÉLULAS PARASITADAS PELO TRYPANOSOMA CRUZI EM CHAGÁSICOS CRÔNICOS
}

\section{Hipólito de Oliveira Almeida, Vicente de Paula Antunes Teixeira, Marlene Antonia dos Reis, José Umberto Franciscon e Elizabeth Martins}

\begin{abstract}
Atra vés do estudo da musculatura-lisa da parede da veia central das supra-renais de chagásicos crônicos foram identificados núcleos em 18 dentre 40 células parasitadas pelo Trypanosoma cruzi. Com o auxilio de uma ocular micrométrica foram tomados dois diâmetros de cada ninho e núcleo, obtendo-se suas médias e desvios padrões $(25,7 \mu \mathrm{m}$ $\pm 17,2$ e $12 \mu \mathrm{m} \pm 5,3$ e 7,5 $\mu \mathrm{m} \pm 2,82$ para diâmetros dos ninhos e dos núcleos para células mononucleadas e binucleadas respectivamente). A relação diâmetro do núcleo/diâmetro do ninho foi de 0,5 $\pm 0,16.83,3 \%$ dos ninhos eram mononucleados e apenas $16,7 \%$ binucleados. A média do volume nuclear para as células parasitadas foi de $1204 \mu^{3} \pm 807,0$ e para as células musculares lisas não parasitadas foi de 69,6 $4 \mathrm{~m} \pm$ 7,2. A forma e o contorno nucleares eram variados e irregulares. Os núcleos hipercromáticos ou vesiculosos, com membrana cromatínica geralmente espessa e bem definida, freqüentemente mostrando um a dois nucléolos por seç̧âo, podendo, no entanto, serem encontrados até 8 nucléolos. Sendo as alterações nucleares descritas freqüentes nos chagásicos crônicos, é possivel que sejam a expressão morfológica de importantes interações entre o T. cruzi e o leiomiócito.
\end{abstract}

Palavras chaves: Doença de Chagas. Trypanosoma cruzi. Supra-renal. Núcleo celular. Célula muscular lisa.

Núcleos volumosos em células parasitadas pelo T. cruzi foram descritos em casos de transmissão congênita da doença de Chagas por Rubio ${ }^{6}$, Rubio e Howard ${ }^{78}$ no esôfago, sendo considerada uma peculiaridade das células fetais 7 . Entretanto, há poucos anos, quando começávamos a estudar as supra-renais de chagásicos crônicos, tivemos a oportunidade de descrever, em 3 chagásicos adultos, ninhos de amastigotas na camada muscular da veia da medular que apresentavam alterações nucleares muito semelhantes àquelas observadas no esôfago de casos congênitos da Tripanosomose americana ${ }^{1}$. $\mathrm{Na}$ época chamamos a atenção para a possibilidade de que o melhor conhecimento do fenômeno poderia auxiliar no entendimento de particularidades da relação hospedeiro-parasita, com potencial importância para o controle do parasitismo. Como não foram feitos estudos morfológicos sistematizados sobre o assunto, o que consideramos ponto de partida para outras abordagens e dispondo de apreciável número de ninhos de amastigotas do $T$. cruzi cujos núcleos são visivelmente alterados, procuramos descrevê-los, ampliando nossas observações anteriores.

\section{MATERIAL E MÉTODOS}

Foram analisados os núcleos encontrados em 18 dentre 40 células parasitadas pelo $T$. cruzi,

Disciplina de Patologia Geral e de Parasitologia da Faculdade de Medicina do Triângulo Mineiro. Praça Manoel Terra s/n. 38100 Uberaba-MG.

Recebido para publicação em 9/9/85. observadas na musculatura lisa da veia da medular das supra-renais de 8 chagásicos crônicos. Para a pesquisa de parasitas na veia da medular das supra-renais temos feito cortes seriados que são corados pela hematoxilina-eosina e analisados ao microscópio. Deste estudo preliminar, as lâminas e os locais dos preparados histológicos que apresentam células parasitadas, cujos núcleos estão presentes, são marcados. As características de cada núcleo eram descritas e dois diâmetros perpendiculares do ninho e de cada um de seus núcleos c/ou lobos nucleares (quando existentes) eram medidos com auxílio de uma ocular micrométrica. A partir destes valores foi calculada a média e desvio padrão para os diâmetros dos ninhos e dos núcleos. A partir dos dois diâmetros de cada ninho e de seu núcleo era obtida a relação diâmetro nuclear/diâmetro do ninho. Quando binucleado o ninho, esta relação era calculada a partir do seu diâmetro médio e da soma dos diâmetros médios de seus núcleos. Baseado na forma de cada núcleo e nos seus diâmetros, calculou-se o seu volume aproximado; quando duplo, lobulado ou irregular, calculava-se o volume das partes de acordo com sua semelhança às figuras geométricas, sendo a estimativa do volume nuclear obtida pela soma dos valores das partes. Para comparação, tomamos dois diâmetros perpendiculares dos núcleos de células musculares lisas em cortes transversais e em cortes longitudinais, nos mesmos segmentos venosos onde se alojavam as células parasitadas pelo T. cruzi. A partir dos diâmetros, calculamos para cada célula muscular não parasitada, vista em corte longitudinal, o volume nuclear, considerando-o um cilindro; deste valor individual foi 
Almeida HO, Teixeira VPA, Reis MA, Franciscon JU, Martins E. Modificaçōes nucleares em células parasitadas pelo Trypanosoma cruzi em chagásicos crônicos. Revista da Sociedade Brasileira de Medicina Tropical 20: 147-152, Jul-Set, 1987.

calculada a média e desvio padrão dos volumes nucleares das células normais.

\section{RESULTADOS}

De um total de 40 células parasitadas (ninhos de T. cruzi) vistas na musculatura lisa da veia da medular das supra-renais, observamos $18(45 \%)$ com núcleos, sendo $15(83,3 \%)$ com apenas um núcleo e $3(16,7 \%)$ com dois núcleos. As médias e os desvios padrões dos diâmetros das células parasitadas (ninhos), dos seus núcleos e dos núcleos das células musculares lisas não parasitadas, estão na Tabela 1 . O teste $t$ de Student mostrou que apenas as diferenças entre os diâmetros dos núcleos das células normais em cortes transversais e das células parasitadas mono e binucleados são altamente significativas $(t=6,12, P<0,01)$ e significativas $(\mathrm{t}=2,36, \mathrm{P}<0,05)$. A Tabela 2 mostra as médias e desvios padrões dos volumes nucleares aproximados das células musculares parasitadas e das células musculares lisas normais, sendo altamente significativas as diferenças observadas $(\mathrm{t}=5,8$, $\mathbf{P}<0,01)$. O coeficiente de correlação de Pearson calculado para os diâmetros dos ninhos e seus núcleos foi de $0,79(\mathrm{P}<0,01)$. Os núcleos das células parasitadas (Fig. 1, 2, 3 e 4), além de volumosos, mostravam contorno irregular com angulações, saliências, bocelações e sulcos ou clivos. Apesar de irregularidade dos núcleos, pode-se dizer que se aproximavam grosseiramente das seguintes formas: oval ( 6 vezes), arredondado (4 vezes), retangular ( 2 vezes), fusiforme ( 2 vezes), lobulado ( 2 vezes), triangular ( $1 \mathrm{vez}$ ), quadrangular ( 1 vez), piriforme (1 vez) e muito irregular ( 2 vezes). Freqüentemente mostravam cromatina condensada na periferia formando uma membrana cromatínica bem marcada, às vezes de espessura irregular. $O$ restante do espaço nuclear pode ser de baixa afinidade tintorial, às vezes bastante claro, outras sendo preenchido por grumos e filamentos grosseiros com grande afinidade pela hematoxilina, podendo ainda ser homogeneamente hipercromático. A maioria dos núcleos mostrava de um, dois, até oito nucléolos, quase sempre

Tabela 1 - Média e desvio padrão dos diâmetros das células parasitadas (dois diâmetros para cada célula), dos diâmetros dos seus núcleos e dos núcleos das células musculares lisas não parasitadas (dois diâmetros para cada núcleo) e da relação entre o diâmetro médio do núcleo e da célula parasitada.

\begin{tabular}{lcccc}
\hline & $\begin{array}{c}\text { N.o de } \\
\text { Células }\end{array}$ & $\begin{array}{c}\text { N.o de } \\
\text { Medidas }\end{array}$ & $\begin{array}{c}\text { Média em } \\
\text { Micrômetro }\end{array}$ & $\begin{array}{c}\text { Desvio } \\
\text { Padrão }\end{array}$ \\
\cline { 2 - 5 } $\begin{array}{l}\text { Diâmetro dos núcleos das células musculares lisas } \\
\text { nāo parasitadas em cortes transversais }\end{array}$ & 10 & 20 & 3,0 & $\pm 0,05$ \\
\hline $\begin{array}{l}\text { Diâmetro dos núcleos das células musculares não } \\
\text { parasitadas em cortes longitudinais }\end{array}$ & 20 & 40 & 10,4 & $\pm 0,6$ \\
\hline $\begin{array}{l}\text { Diâmetro das células parasitadas } \\
\text { Diâmetro dos núcleos das células parasitadas } \\
\text { quando únicos por célula }\end{array}$ & 18 & 36 & 25,7 & $\pm 17,2$ \\
\hline $\begin{array}{l}\text { Diâmetro dos núcleos das células parasitadas } \\
\text { quando binucleadas }\end{array}$ & 3 & 30 & 12,0 & $\pm 5,3$ \\
\hline $\begin{array}{l}\text { Relação diâmetro nuclear/diâmetro celular para as } \\
\text { células parasitadas }\end{array}$ & 18 & 12 & 7,5 & $\pm 2,8$ \\
\hline
\end{tabular}

Tabela 2 - Volume nuclear aproximado calculado para células musculares lisas parasitadas (em cortes longitudinais) e parasitadas pelo Trypanosoma cruzi na parede da veia central das supra-renais de chagásicos crônicos.

\begin{tabular}{lccc}
\hline & $\begin{array}{c}\text { No de } \\
\text { Células }\end{array}$ & $\begin{array}{c}\text { Média } \\
\text { em micrómetros } 3\end{array}$ & $\begin{array}{c}\text { Desvio } \\
\text { Padrão }\end{array}$ \\
\cline { 2 - 4 } & & 69,6 & $\pm \quad 7,2$ \\
\hline $\begin{array}{l}\text { Volume nuclear das células musculares lisas não parasi- } \\
\text { tadas em cortes longitudinais }\end{array}$ & 20 & 1204,7 & $\pm 807,0$ \\
\hline Volume nuclear das células parasitadas & 18 & 120 \\
\hline
\end{tabular}


Almeida HO, Teixeira VPA, Reis MA, Franciscon JU, Martins E. Modificações nucleares em células parasitadas pelo Trypanosoma cruzi em chagásicos crônicos. Revista da Sociedade Brasileira de Medicina Tropical 20: 147-152, Jul-Set, 1987.

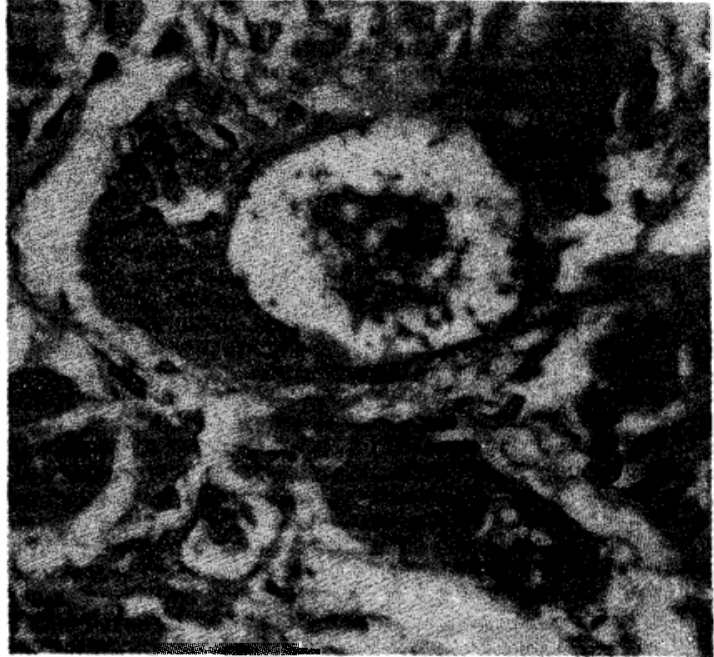

Fig. 1 - Musculatura lisa da veia da supra-renal de chagásico crônico - Observa-se uma célula parasitada apresentando núcleo volumoso, de contorno irregular. O citoplasma é claro e contém poucas formas amastigotas. Hematoxilina-eosina, $x 400$.

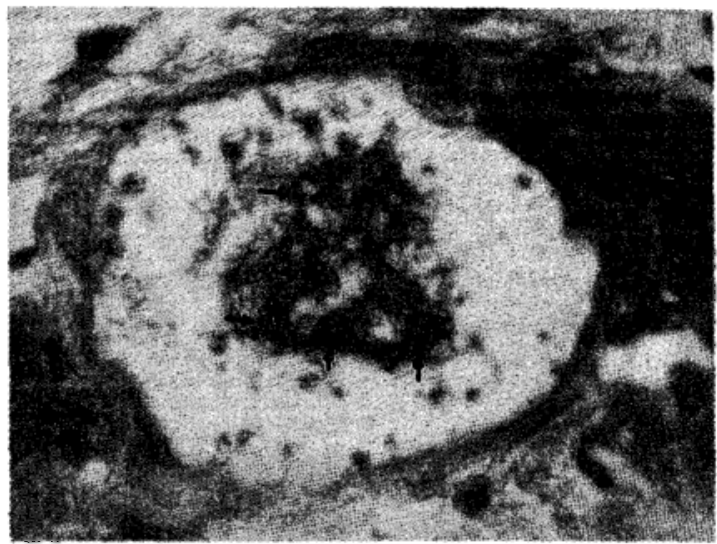

Fig. 2 -Detalhe da figura anterior - Observar o núcleo gigante, atípico, com vários nucléolos (setas). Hematoxilina-eosina, x1000.

volumosos, às vezes contendo material acidófilo. As células musculares lisas não parasitadas, quando em cortes transversais, têm núcleos com secção circular ao passo que seus cortes longitudinais exibem núcleos bastante longos (entre 15 e 20 micrômetros) com diâmetro transversal semelhante aos vistos em cortes longitudinais, permitindo considerá-los cilíndricos.

\section{DISCUSSÃO}

O presente estudo confirma e amplia observações anteriores, realizadas em nosso laboratório,

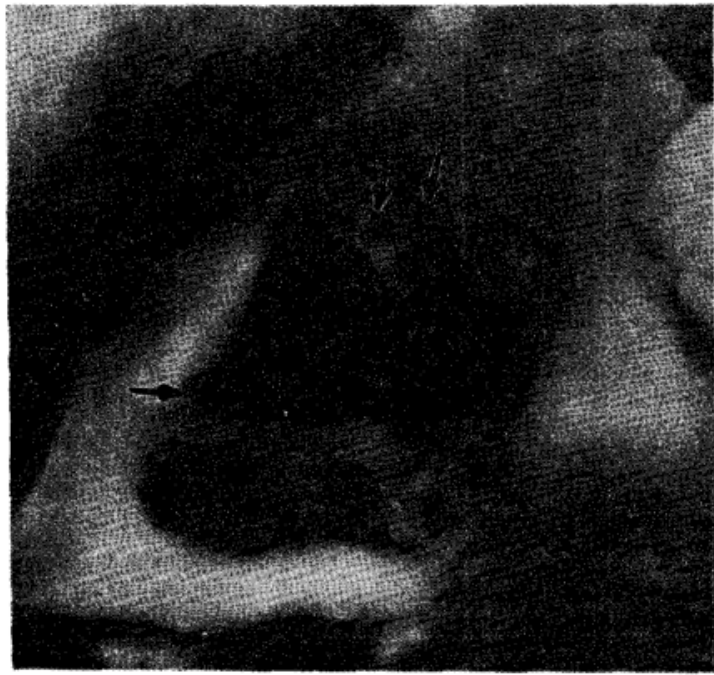

Fig. 3 - Célula parasitada na muscular da veia da supra-renal de chagásico crônico. $O$ citoplasma está parcialmente retraído, contendo poucas amastigotas (setas). São vistos dois núcleos hipercromáticos. Hematoxilinaeosina, $\times 1000$.

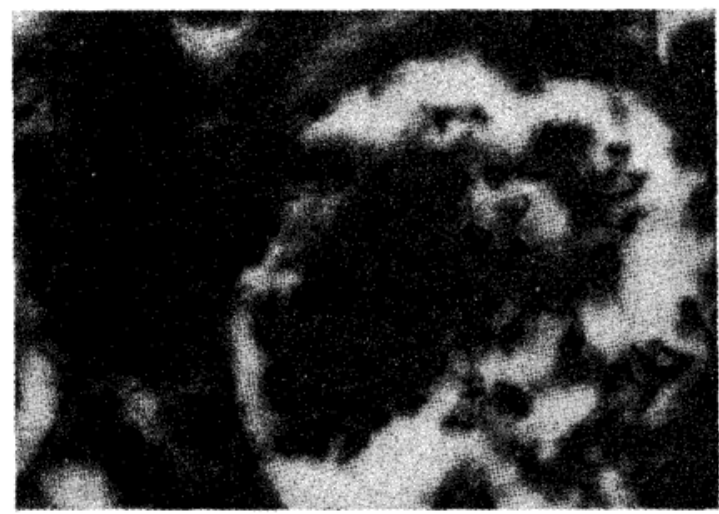

Fig. 4 - Célula parasitada na musculatura da veia da supra-renal de chagásico crônico - Os parasitas são mais numerosos e o núcleo é volumoso, homogeneamente carado e sem limites nitidos, sugerindo alterações regressivas do mesmo. Hematoxilina-eosina, x1000.

sobre modificações nucleares em células parasitadas pelo $T$. cruzi, nas supra-renais de chagásicos crôni$\cos ^{1}$. Ao analisar 40 ninhos do $T$. cruzi na parede da veia da medular das supra-renais destes chagásicos, encontramos núcleos em 18(45\%) deles, todos atipi$\cos$, bem mais volumosos que nas células musculares não parasitadas. Esta freqüência nos permite afirmar que as modificações nucleares não representam uma característica das células fetais, como admitiram Rubio e Howard?.

Não há uma forma nuclear constante, sendo esta geralmente atípica, aproximando com freqüência 
Almeida HO, Teixeira VPA, Reis MA, Franciscon JU, Martins E. Modificaçóes nucleares em células parasitadas pelo Trypanosoma cruzi em chagásicos crônicos. Revista da Sociedade Brasileira de Medicina Tropical 20: 147-152, Jul-Set, 1987.

do aspecto ovóide ou arredondado e, menos freqüentemente, do triangular, retangular ou piriforme, podendo ainda o núcleo ser muito irregular e lobulado. A cromatina pode ser condensada na periferia, sendo o resto do núcleo claro contendo de um até 8 nucléolos, ou ser formada por grumos e filamentos grosseiros, distribuídos por todo o núcleo, mostrando um padrão de organização do material genético bastante diverso do observado nas células normais. Mais raramente o núcleo é de aspecto homogeneamente hipercromático, semelhante aos picnóticos, o que poderia representar a morte da célula hospedeira e provável interrupção do ciclo intracelular do parasitismo.

Embora na maioria ( $82,3 \%$ ) das células parasitadas o núcleo seja único, algumas podem ser binucleadas $(16,7 \%)$. Quando únicos, têm um diâmetro médio de quase o dobro dos núcleos duplos ( $12 \pm 5,3$ e 7,5 $\pm 2,8$ micrômetros respectivamente) sendo ambos os valores significativamente superiores à média dos diâmetros nucleares das células não parasitadas vistas em cortes transversais. Como as células normais têm um núcleo muito alongado e estreito e as células parasitadas têm núcleos e diâmetros pouco diferentes. a comparação dos diâmetros dos núcleos das células normais em cortes longitudinais com os diâmetros das células parasitadas não mostra diferenças significativas $(P>0,05)$. Os maiores valores dos desvios padrões das médias dos diâmetros dos núcleos das células parasitadas mono e binucleadas quando comparadas às normais se explicam pela grande variação do tamanho dos núcleos das primeiras o que, provavelmente estaria associado à evolução do parasitismo intracelular. Por outro lado, o aumento do diâmetro nuclear guarda boa correlação com o aumento de diâmetro do ninho, como o demonstram o coeficiente de correlação de Pearson relativamente alto $(r=0,79$, $\mathrm{P}<0,01)$ e o baixo desvio padrão da média da relação diâmetro nuclear/diâmetro do ninho. $O$ volume nuclear aproximado, calculado para os ninhos, foi muito superior (quase 20 vezes) ao das células musculares lisas não parasitadas da parede venosa $(P<0,01)$. Fizemos a comparação das células parasitadas com as musculares lisas normais, porque em estudos anteriores ${ }^{19}$ colhemos dados bastante convincentes de que as células parasitadas da veia suprarrenálica são leiomiócitos. Estão sempre na intimidade dos fascículos musculares da veia, jamais entre as células do conjuntivo peri e interfascicular; em algumas células com núcleos atipicos gigantes, podem ser observados feixes de miofibrilas. Recentemente, estudando ao microscópio eletrônico células parasitadas da veia umbilical na doença de Chagas congênita, com características semelhantes às que descrevemos na veia suprarrenálica, Lana ${ }^{5}$ constatou sua natureza muscular. Aliás, Barbosa Jr. e Andrade 4 ao estudarem células parasitadas pelo $T$. cruzi no tubo digestivo e na veia da medular das supra-renais de chagásicos crônicos, são taxativos em admitirem sua natureza muscular.

Embora algumas das alterações nucleares observadas nos tecidos fetais e na veia das suprarenais de chagásicos crônicos adultos possam ser consideradas apenas um efeito colateral do parasitismo intracelular, a hipertrofia nuclear e a freqüente presença de nucléolos, às vezes numerosos, sugerem intensa atividade nuclear e produção de RNA ribossômico, induzidas pelo parasitismo, devendo desempenhar importante papel no ciclo de reprodução e diferenciação que o $T$. cruzi realiza no interior das células musculares lisas do hospedeiro vertebrado. Como o T. cruzi continua participando da gênese da inflamação no miocárdio de chagásicos crônicos ${ }^{3}$ e a veia da medular das supra-renais parece ser uma espécie de reservatório do parasita de onde o mesmo pode ser liberado periodicamente e assim perpetuar a agressão a outros órgāos ${ }^{2}$, o esclarecimento de todos os detalhes desta relação tem potencial importância na busca de caminhos terapêuticos mais eficazes para a fase crônica da doença de Chagas.

\section{$S U M M A R Y$}

By the study of histological sections of smooth muscle in the wall of the adrenal vein in human chronic Chagas'disease 18 nuclei were identified in 40 cells parasitized by $\mathrm{T}$. cruzi. With an ocular micrometer two diameters of each nest and their nucleus were taken, obtaining their mean size and standard deviation $(S D)(25.7 \mu \mathrm{m} \pm 17.2$ for nest diameters and $12 \mu \mathrm{m} \pm 5.3$ and $7.5 \mu \mathrm{m} \pm 2.82$ for the nuclear diameters of the mononucleated and binucleated cells respectively). The relation mucleus diameter/nest diameter was $0.5 \pm 0.16 .83 .3 \%$ of the nests had one nucleus and $16.7 \%$ were binucleated. The mean nuclear volume of the parasitized cells was $1204 \mu^{3} \pm 807.0$ and of the non parasitized smooth muscle cells was $69.6 \mu \mathrm{m}^{3} \pm 7.2$. Nuclear form and outline were varied and irregular. Hyperchromatic or vesicular nuclei, with a large and well defined chromatinic membrane usually show in cells one or two nucleoli per section but this number can reach 8 nucleoli. These nuclear alterations frequently seen in the wall of the adrenal vein of chagasic patients could be significant in the intracellular cycle of $\mathrm{T}$. cruzi in the leiomyocyte.

Key words: Chagas' disease. Trypanosoma cruzi. Adrenal gland. Nucleus. Smooth muscle cell.

\section{REFERÊNCIAS BIBLIOGRÁFICAS}

1. Almeida HO, Teixeira VPA, Oliveira ACF. Alterações nucleares em células parasitadas pelo $T$. cruzi. Revista de Patologia Tropical 10:15-20, 1981. 
2. Almeida HO, Teixeira VPA, Oliveira ACF. Flebite com parasitismo em supra-renais de chagásicos crônicos. Arquivos Brasileiros de Cardiologia 36:341-344, 1981.

3. Almeida HO, Teixeira VPA, Gobbi H, Rocha A, Brandāo MC. Inflamaçāo associada a células musculares cardíacas parasitadas pelo Trypanosoma cruzi, em chagásicos crônicos. Arquivos Brasile.ros de Cardiologia 42:183-186, 1984.

4. Barbosa Jr AA, Andrade ZA. Identificação do Trypanosoma cruzi nos tecidos extracardíacos de portadores de miocardite crônica chagásica. Revista da Sociedade Brasileira de Medicina Tropical 17:123-126, 1984.

5. Lana AMA. Estudo morfológico da placenta na Doença de Chagas materna. Contribuição da imunocitoquímica e da microscopia eletronica. Tese de Mestrado. Universidade Federal de Minas Gerais, Belo Horizonte, 1986.
6. Rubio M. Compromiso del esofago en dos casos de enfermedad de Chagas congênita. Bolletin Chileno de Parasitologia 23:157-163, 1968.

7. Rubio M, Howard J. Observation de células gigantes parasitadas por Trypanosoma cruzi en niños con enfermedad de Chagas congênita. Biologica 34:50- $C 0$, 1963.

8. Rubio M, Howard J. Congenital Chagas' disease. II Pathological findings in nine cases. Bolletin Chileno de Parasitologia 23:113-120, 1968.

9. Teixeira VPA. Parasitismo da veia central da suprarenal em diferentes formas anátomo-clínicas da Doença de Chagas. Tese de Mestrado. Universidade Federal de Minas Gerais, Belo Horizonte, 1985. 